\title{
Design and Optimization of Steel Car Body Structures via Local Laser-Strengthening
}

\author{
Markus Wagner ${ }^{1,2 *}$, Axel Jahn1, Eckhard Beyer ${ }^{1,2}$, Daniel Balzani',3 \\ ${ }^{1}$ Division of Laser Beam Joining, Fraunhofer Institut $\mathrm{f}$. Werkstoff- und Strahltechnik, Dresden, Germany \\ ${ }^{2}$ Dresden Center for Computational Materials Science, Dresden University of Technology, Dresden, Germany \\ ${ }^{3}$ Institute of Mechanics and Shell Structures, Dresden University of Technology, Dresden, Germany \\ Email: *markus.wagner@iws.fraunhofer.de
}

Received 25 March 2016; accepted 14 May 2016; published 17 May 2016

Copyright (C) 2016 by authors and Scientific Research Publishing Inc.

This work is licensed under the Creative Commons Attribution International License (CC BY).

http://creativecommons.org/licenses/by/4.0/

(c) $\underset{\mathrm{EY}}{\mathrm{B}}$ Open Access

\section{Abstract}

Continuously rising demands of legislators require a significant reduction of $\mathrm{CO}_{2}$-emission and thus fuel consumption across all vehicle classes. In this context, lightweight construction materials and designs become a single most important factor. The main engineering challenge is to precisely adapt the material and component properties to the specific load situation. However, metallic car body structures using "Tailored blanks" or "Patchwork structures" meet these requirements only insufficiently, especially for complex load situations (like crash). An innovative approach has been developed to use laser beams to locally strengthen steel crash structures used in vehicle bodies. The method tailors the workpiece hardness and thus strength at selected locations to adjust the material properties for the expected load distribution. As a result, free designable 3D-strengtheningpatterns surrounded by softer base metal zones can be realized by high power laser beams at high processing speed. The paper gives an overview of the realizable process window for different laser treatment modes using current high brilliant laser types. Furthermore, an efficient calculation model for determining the laser track properties (depth/width and flow curve) is shown. Based on that information, simultaneous FE modelling can be efficiently performed. Chassis components are both statically and cyclically loaded. Especially for these components, a modulation of the fatigue behavior by laser-treated structures has been investigated. Simulation and experimental results of optimized crash and deep drawing components with up to $55 \%$ improved level of performance are also illustrated.

\section{Keywords}

Automotive Lightweight Structures, Local Laser Treatment, Laser Beam Strengthening, Crash Simulation, Laser Strengthening, Laser Hardening

\footnotetext{
"Corresponding author.
} 


\section{Introduction}

Car body structures for small and mid-range segments that are particularly suited for large-scale production are predominantly made of steel or steel intensive constructions [1]. Basically, the car body components are subjected to static, dynamic (crash) and even complex fatigue loads [2] [3]. The main engineering challenge is to adapt the material and component properties to single and superimposed load situations. For that strategy, different lightweight manufacturing technologies especially for steel materials already exist. The most common products and technologies in car body manufacturing are "tailored components" (blanks and tubes), "patchwork structures" and "profiling technologies" (for detailed information see [1] [3]-[5]). In all cases, either the material thickness or strength is locally customized (Figure 1(a)). Furthermore, lightweight concepts for body-in-white applications using metallic hybrid constructions, like aluminum-steel structures, are becoming more and more attractive. However, the required efficient joining technologies, especially for crash-suitable hybrid body structures are not sufficiently applicable up to now [8].

Crash deformations mostly lead to complex load situations in special component areas (Figure 1(b)) that cannot sufficiently be covered by conventional designs and manufacturing technologies [9] [10]. Furthermore, in some cases only small adjustments of component properties are necessary. That applies especially to multipleused modular car body designs, vehicle derivatives or adjustments in series production (e.g. variations in material quality) to meet the quality requirements [11]. Minor adjustments of conventional production technologies mostly induce high efforts and costs because of their low manufacturing flexibility. Hence, it is necessary to develop novel large-scale technologies for precisely and flexibly adapting the component properties to the localized load situations. Predominantly experimental investigations of prior research studies ([12]-[15]) prove that the material strength of steel sheets can be efficiently adjusted by a local laser-strengthening process. As a result, significant improvements of the crash energy absorption capability, deep drawing properties and manufacturing flexibility were achieved. In order to design local laser-strengthened structures, especially for complex component geometries or load situations, numerical simulations are mandatory [9] [16]. In this context, the paper shows technical and mathematical possibilities for the determination and the subsequent implementation of required laser track material and dimensional data into FE models. Different numerical design approaches, especially for optimizing crash components are illustrated. Furthermore, experimental crash and fatigue test results of untreated and laser-strengthened samples are presented.

In conclusion, the localized laser-strengthening process can make a valuable contribution to innovative steelbased automotive lightweight designs, improved passive vehicle safety and flexible car body manufacturing.

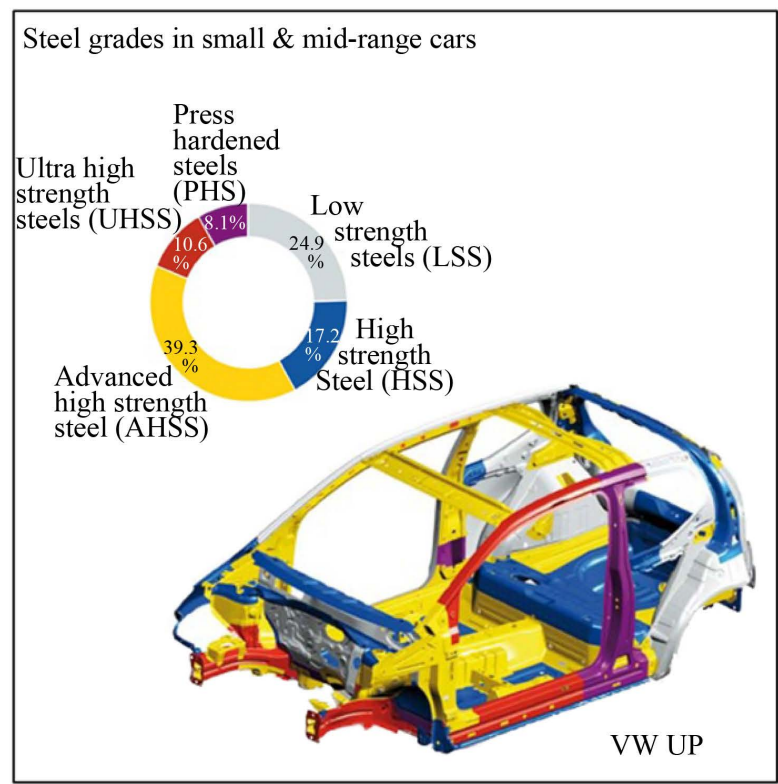

(a)

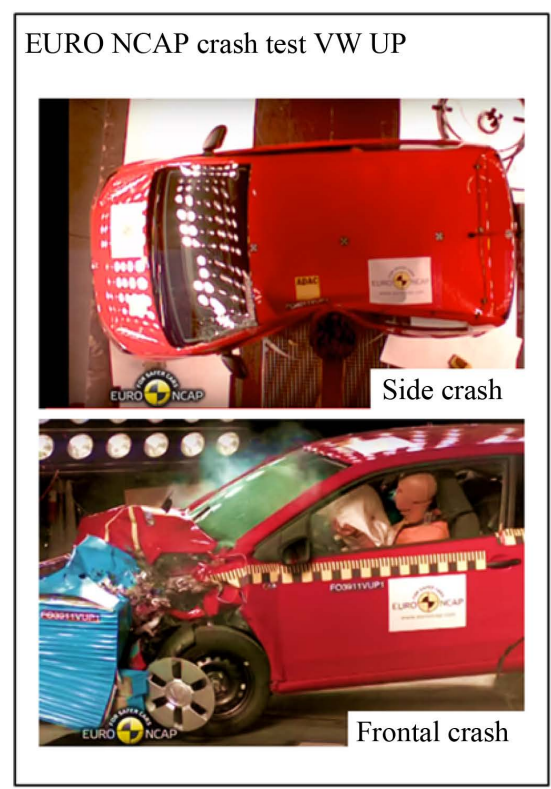

(b)

Figure 1. Steel intensive light weight construction at VW UP (a) (taken from [6]), complex component deformation induced by different crash test regulations (b) (taken from video in [7]). 
Using already established laser technology for other processes (like welding or brazing), the technique can be easily integrated into existing large-scale manufacturing processes.

\section{Laser Based Material Strengthening}

The laser-strengthening approach aims at using low cost low strength steel (LLS), high strength steel (HSS) or even advanced high strength steel (AHSS) sheets with reduced wall thicknesses (see Figure 1(a)). These sheets could be laser treated in order to strengthen the material at locations with high loads. The focused laser beam is moved across the surface at defined speed. The concentrated energy deposition heats or even melts the laser track. The subsequent cooling leads to martensitic hardening of such steels that are typically used in the automotive industry. The tensile strength in the treated zones can be 2.4 times higher compared to the base material (e.g. see [9]). The maximum process efficiency, resulting laser track strength values and series production suitability can be achieved by the laser remelting process. Therefore, that laser treatment mode will be focused in the following sections.

\subsection{Laser Beam Remelt-Strengthening: Process and Characteristics}

The process of laser beam remelt-strengthening aims at tailoring the workpiece hardness and thus strength at selected locations to adjust the material properties to the expected load distribution. The strengthening effect bases on martensitic hardening of low alloyed steels which comes along with a significant strength increase. That specific material transformation can be achieved by heating up the material over austenitizing temperature followed by rapid cooling down. For solid state processes (conventional inductive or oven-hardening), the austenite transformation is time- and temperature-controlled. In the case of laser beam remelt-strengthening, the local material temperature is significantly higher than the melting temperature. Accordingly, the austenitizing process is not determined by diffusion and thus significantly faster. For melting the material one or even more simultaneous laser beams with high beam intensities (typical values $\mathrm{I} \approx 5 \times 10^{5} \cdots 5 \times 10^{6} \mathrm{~W} / \mathrm{cm}^{2}$ [17]) can be used. The focused laser beam is moved linearly (Figure 2(a)) at defined speed by portal machines or alternatively, it is scanned across the surface by scanning optics. The highly concentrated energy input enables melting and thus complete austenitizing in a very short period of time. Through free or forced cooling, the microstructure of hardenable steels converts into a martensitic structure with high hardness and thus high strength.

The laser track properties depend on the specific laser process parameters (e.g. laser power $P_{L}$, focus diameter

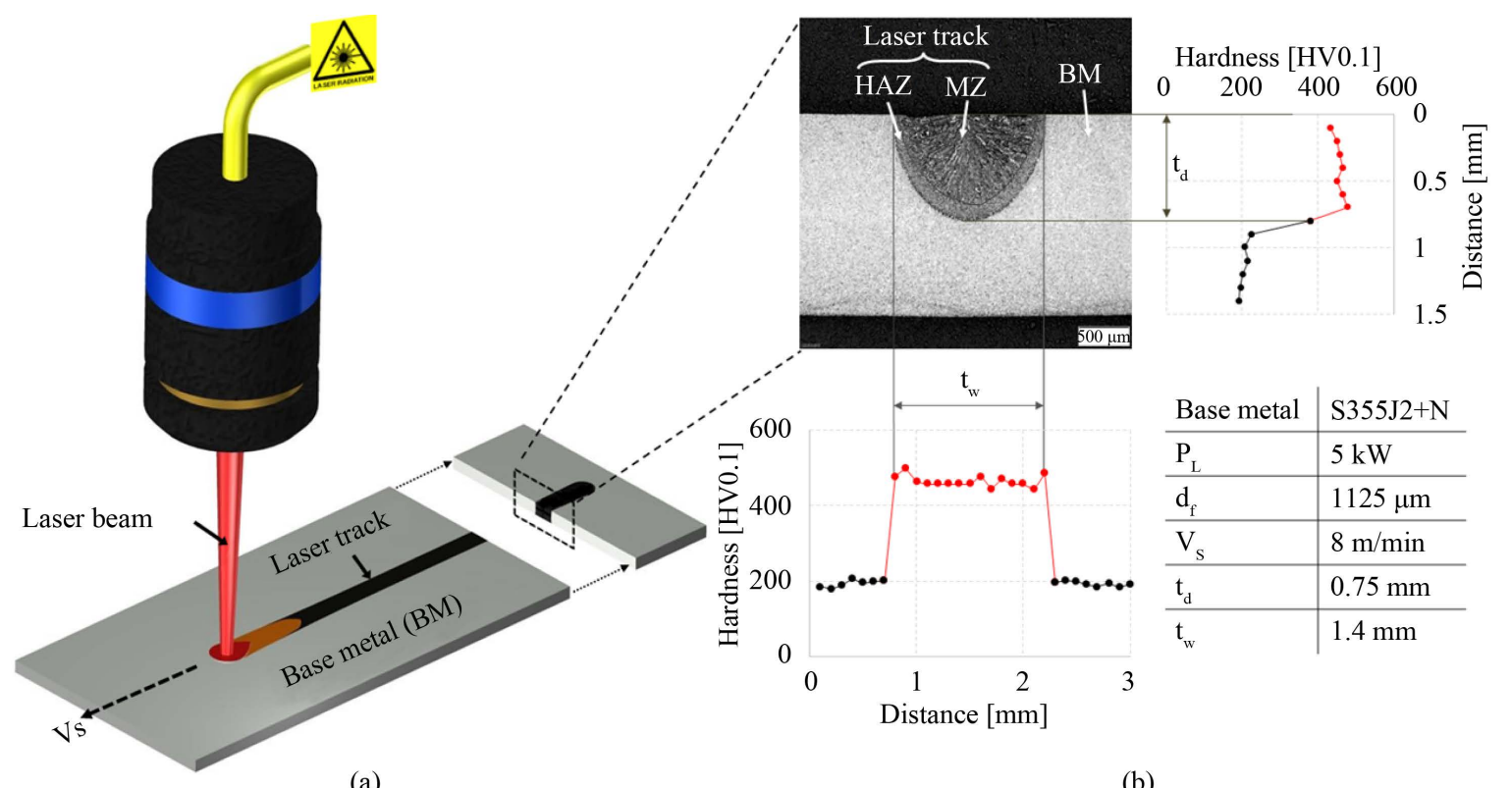

(a)

(b)

Figure 2. Laser beam remelt-strengthening process (a), resulting cross section (etched with $2 \%$ Nital) and hardness distribution for an exemplary material (low alloyed steel grade) and set of process parameters (b). 
$d_{f}$ and feed rate $v_{s}$ ) and the material composition. For numerically designing load adapted laser track patterns the following 2 track properties are essential (see Figure 2(b)):

- Strengthening dimensions: Laser track depth $\left(t_{d}\right)$ and width $\left(t_{w}\right)$.

- Laser track hardness or more precisely: the flow curve of the laser track.

The laser track depth and width can be precisely determined by microhardness measurements (e.g. Vickers microhardness HV 0.1). From Figure 2(b) it is apparent, that not only the melt zone (MZ), but also the heat affected zone (HAZ) shows a significantly higher hardness level compared to the base metal (BM). The hardness level at the HAZ can vary largely according to the specific base material characteristics. For the definition of the laser track dimensions $\left(t_{d}, t_{w}\right)$ the HAZ must necessarily be considered.

Figure 3(a) gives an overview about achievable hardness levels of the laser track (averaged over MZ and HAZ). It is obvious that for all selected steel grades a significant increase in hardness compared to the base metal can be achieved. Generally, hardness increase is associated with a respective increase in material strength (strengthening). Consequently, the laser track zone exposes a significant higher level of yield and flow strength (Figure 3(b)).

"Simultaneous engineering" in car body dimensioning that is based on numerical calculations is becoming more and more attractive. Such numerical models require the stress-strain-behavior in the form of flow curves for each separate material condition (BM, HAZ, MZ). The dimensions of the thermally treated zones are usually very small (e.g. $1 \times 1 \mathrm{~mm}$ ). Therefore, conventional methods for determining the flow curve (standardized tensile test, compression or bulge test) are not applicable. For most of the LSS, HSS and AHSS the properties of the MZ and the HAZ can be merged. Exactly for these materials at Fraunhofer IWS a special tensile test specimen, called "micro tensile test specimen" was developed. The standardized tensile specimen shape (DIN EN ISO 6892-1) was adapted to the track dimensions, with the result that the examination area completely consists of MZ. The contour is wire eroded and subsequently surface grinded to avoid annealing effects and to ensure reproducible test conditions (Figure 3(b)). Tensile tests with quasi-static and higher strain rates for both material conditions (BM and MZ) were examined. For the laser track condition higher strain rates play a minor roll, because the strain rate sensitivity decreases with higher hardness and strength [18]. As a result of the described experimental examinations the required information for a crash or deep drawing simulation of laser treated structures can be determined quite precisely.

\subsection{Calculation Models for Determining the Laser Track Properties}

Because of the wide range of available materials and possible laser process parameters, the effort for experimentally determining the laser track properties is quite high. In most cases of optimizing and pre-designing car body components, high-precision data are not necessary. Exactly for that case a novel approach was developed, with the objective to calculate the necessary laser track properties for the simulation model by the given base material characteristics and estimated laser process parameters (Figure 4).

The laser beam remelt process is quite similar to the laser beam welding process. Therefore, most of the welding correlations can be merged. First of all the laser treatment mode must be checked. It is important to distinguish between two melting effects: heat conduction and deep melting effect. High process efficiency levels

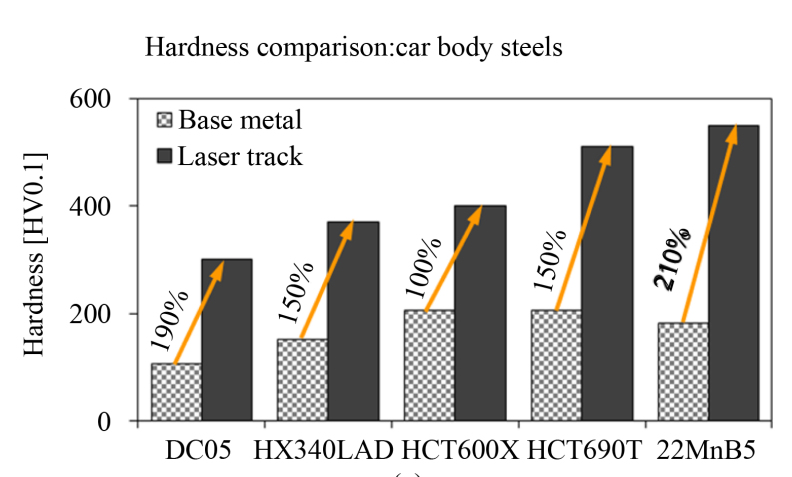

(a)

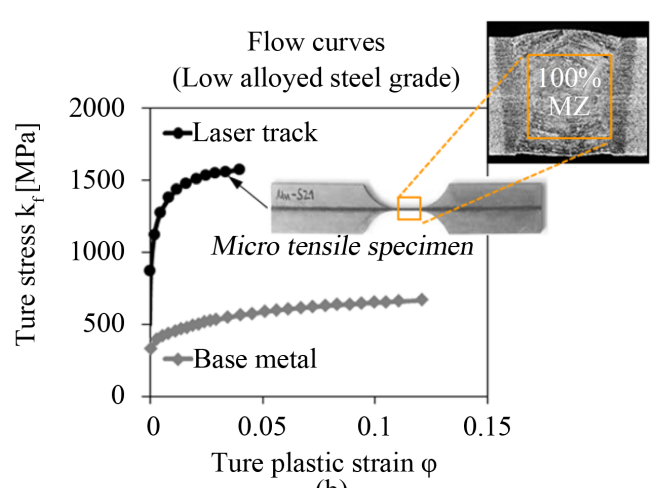

(b)

Figure 3. Achievable increase in hardness for different laser remelt-strengthened car body steel grades (a), determination of flow curves for base metal and melt zone condition using the "micro tensile test specimen" (b). 


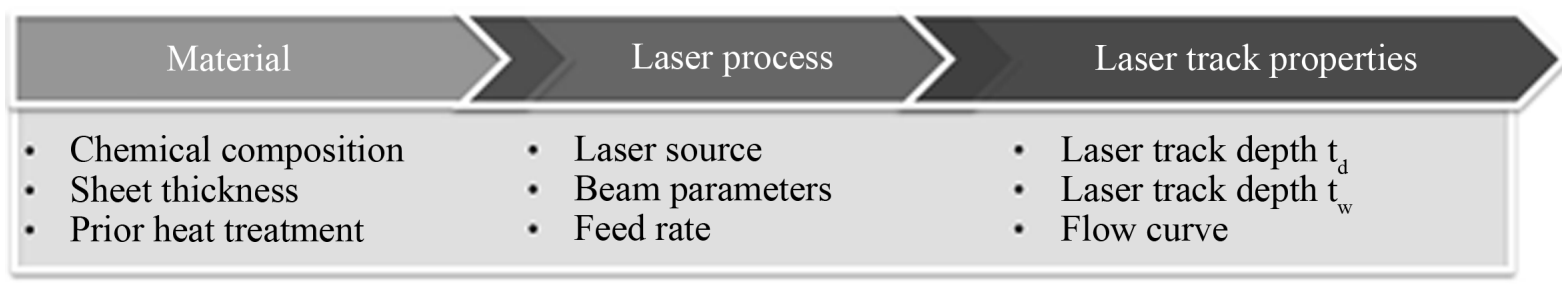

Figure 4. Novel approach for the mathematical calculation of laser track properties by material and laser process parameters.

can only be achieved by ensuring the deep melting effect. According to [19] for Gaussian beam shape profiles the Equation (1) must be met. According to [20] the required intensity quotient $P_{L} / d_{f}$ increases for Tophat beam shape profiles by the factor of 1.25 . Nevertheless, typically used steel grades and laser beam intensities $(\mathrm{I} \approx 5 \times$ $10^{5} \cdots 5 \times 10^{6} \mathrm{~W} / \mathrm{cm}^{2}$ ) certainly satisfy Equation (1).

$$
\frac{P_{L}}{d_{f}}>\frac{T_{v} \cdot \lambda_{t h}}{A_{L}} \sqrt{\frac{P e}{4}+1.1} \text { with } P e=\frac{d_{F} \cdot v_{S}}{2 \cdot \kappa}
$$

The calculation of the resulting laser track depth $t_{d}(2)$ and width $t_{w}(3)$ requires approximate models for deep melting modes and moving cylindrical heat sources [21]. An overview about the symbols and its descriptions can be found in Table 1.

$$
\begin{gathered}
t_{d}=\frac{P_{L}}{d_{F} v_{S}} \cdot \frac{1}{\rho c_{P} \Delta T\left(1+\left(\frac{P e}{2}\right)^{-0.7}\right)+\rho\left(\varepsilon_{S}+\delta \varepsilon_{V}\right)} \\
t_{w} \approx d_{F}\left(1+\left(\frac{P e}{2}\right)^{-0.7}\right)
\end{gathered}
$$

In order to verify the calculation approach, Figure 5 shows the comparisons of calculated and experimental results for the laser remelt-strengthening process. The results are based on a commonly used dual phase steel grade (HCT600X) and typical laser process parameters. For the calculation several assumptions, based on standard material properties of ferritic steel were made. The calculated results achieved a good correlation with the experimental results and thus verified the procedure to estimate the laser track depth and width according to the material and process parameters.

Finally the specific strength characteristics of the laser track must be determined mathematically. It was observed in [9] that there is a direct correlation between the martensitic laser track hardness and the examined tensile strength. Together with the strain hardening coefficient a flow curve can be described with the Reihle-Nadai-approach, for unalloyed and low alloyed steel grades [22]. Therefore, the first step is the calculation of the achievable laser track hardness that is predominantly controlled by the chemical composition of the base material. For determining that correlation a multiple linear regression was performed, that is taking 18 different material compositions (low alloyed steel grades) and typical remelt process parameters into account [17]. Finally the correlation between the most relevant alloying elements and the resulting averaged microhardness of the laser track is obtained with a standard deviation of $26 \mathrm{HV}$ (for the 18 examined materials) (4).

$$
\begin{aligned}
\text { HV0.1 } 1_{\text {Laser } \cdot \text { track }}= & 203+829 \cdot \mathrm{C}+221 \cdot \mathrm{Si}+40 \cdot \mathrm{Mn}+585 \cdot \mathrm{Ni} \\
& -72 \cdot \mathrm{Cr}+67 \cdot \mathrm{Mo} \quad \text { Alloying elements in [mass-\%] }
\end{aligned}
$$

Subsequently, the calculated laser track hardness value could be converted into the tensile strength $\left(R_{m}\right)$. That correlation was found in [9] and is shown in Equation (5).

$$
R_{m, \text { Laser track }} \approx 2.9 \cdot \mathrm{HV} 0.1_{\text {Laser-track }}
$$

According to the examinations in [9] the strain hardening coefficient of the martensitic transformed laser track is almost equal to 0.04 . Finally, the flow curve description by Reihle-Nadai [22] can be completely described. That model also can be used to extrapolate flow curves to high strain values. The flow curve description approach is shown in Equation (6). For a description of the individual symbols see Table 2. 
Table 1. Symbols and descriptions for Equations (1)-(3).

\begin{tabular}{cccccc}
\hline Symbol & Unit & Description & Symbol & Unit & Description \\
\hline$A_{L}$ & - & Absorption coefficient for laser radiation & $t_{w}$ & $\mathrm{~mm}$ & Laser track width \\
$c_{p}$ & $\mathrm{~J} \cdot \mathrm{kg}^{-1} \cdot \mathrm{K}^{-1}$ & Specific heat capacity & $v_{s}$ & $\mathrm{Mm} \cdot \mathrm{min}^{-1}$ & Feed rate \\
$d_{f}$ & $\mu \mathrm{m}$ & focus diameter & $\varepsilon_{S}$ & $\mathrm{~J} \cdot \mathrm{kg}^{-1}$ & Melting enthalpy \\
$P e$ & - & Peclet-number & $\varepsilon_{V}$ & $\mathrm{~J} \cdot \mathrm{kg}^{-1}$ & Evaporation enthalpy \\
$P_{L}$ & $\mathrm{~W}$ & Laser power & $\kappa$ & $\mathrm{cm}^{2} \cdot \mathrm{s}^{-1}$ & Conductibility of temperature \\
$T$ & $\mathrm{~K}$ & Temperature & $\lambda_{\text {th }}$ & $\mathrm{W} \cdot \mathrm{cm}^{-1} \cdot \mathrm{K}^{-1}$ & Thermal conductivity \\
$T_{V}$ & $\mathrm{~K}$ & Evaporating temperature & $\rho$ & $\mathrm{Kg} \cdot \mathrm{m}^{-3}$ & Density \\
$t_{d}$ & $\mathrm{~mm}$ & Laser track depth & & & \\
\hline
\end{tabular}

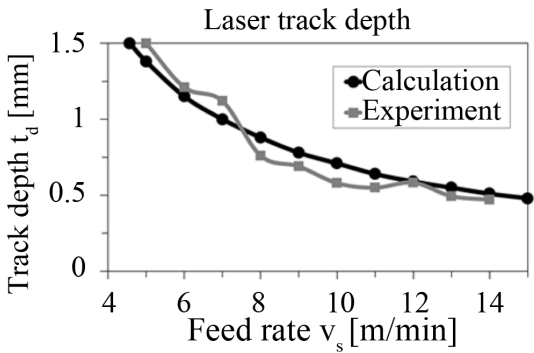

(a)

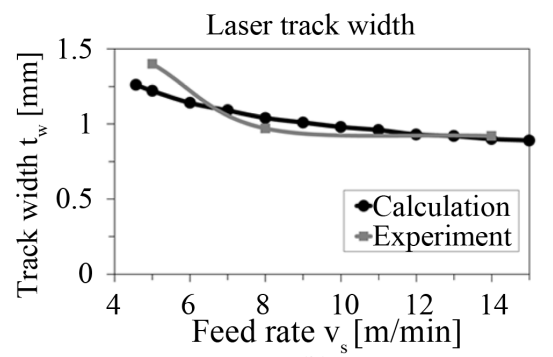

(b)

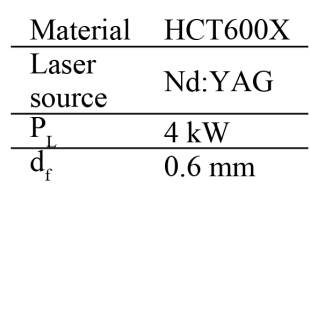

(c)

Figure 5. Comparisons of calculated and experimental results for the laser remelt-strengthening process: Laser track depth (a), Laser track width (b), Exemplary process parameters (c).

Table 2. Symbols and descriptions for Equation (6).

\begin{tabular}{cccccc}
\hline Description & Euler number & Flow stress & Strain hardening coefficient & Tensile strength & True strain \\
\hline Unit & - & $\mathrm{MPa}$ & - & $\mathrm{MPa}$ & - \\
Symbol & $\mathrm{e}$ & $\mathrm{k}_{\mathrm{f}}$ & $\mathrm{n}$ & $\mathrm{R}_{\mathrm{m}}$ & $\varphi$ \\
\hline
\end{tabular}

$$
k_{f, \text { Laser track }}=R_{m, \text { Laser track }} \cdot\left(\frac{e}{n}\right)^{n} \cdot \varphi^{n}
$$

For two exemplary steel grades, Figure 6 shows the comparison of the calculated and experimental flow curves for the laser beam remelt-strengthened track. The two diagrams show a good correlation between calculation and experimental results. Further improvements of the correlation accuracy can be achieved by examining more materials and process parameters. Note that here only 18 different material compositions were taken into account. For a good accuracy of the regression results, significantly more material data would be adequate.

In conclusion, a calculation approach for determining the laser track properties only by knowing the base material composition and the laser process parameters could be developed and verified. Potential improvements of correlation accuracy with the experimental results have been described. The calculation approach is best suited for efficiently optimizing and pre-designing of car body components.

\section{Load Adapted Component Design via Local Laser-Strengthening}

\subsection{Numerical Design of Laser-Strengthened Structures}

Laser remelted structures usually consist of the three material zones: Base material (BM), heat affected zone (HAZ) and the melt zone (MZ). If all zones were included into the FE model and an equidistant FE discretization is applied, the minimum element edge length $\left(\mathrm{l}_{\mathrm{E} \min }\right)$ is very small (Figure $7(\mathrm{a})$ ). However, the common element edge length for complete vehicle crash simulations is currently about $3 \cdots 5 \mathrm{~mm}$ [11]. For most of the LSS, HSS and AHSS, the properties of the MZ and the HAZ can be merged, and thus only two zones with 


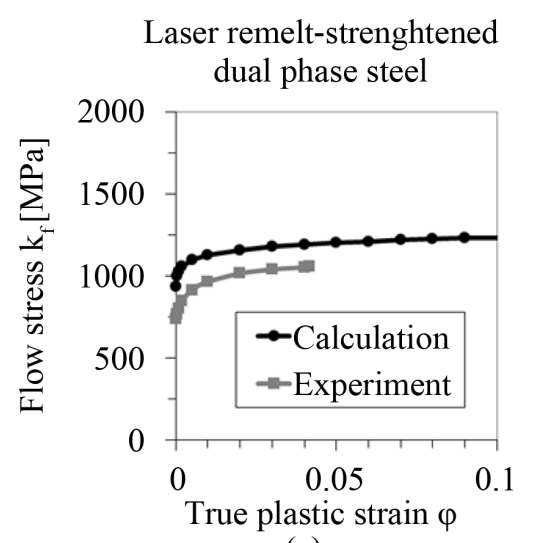

(a)

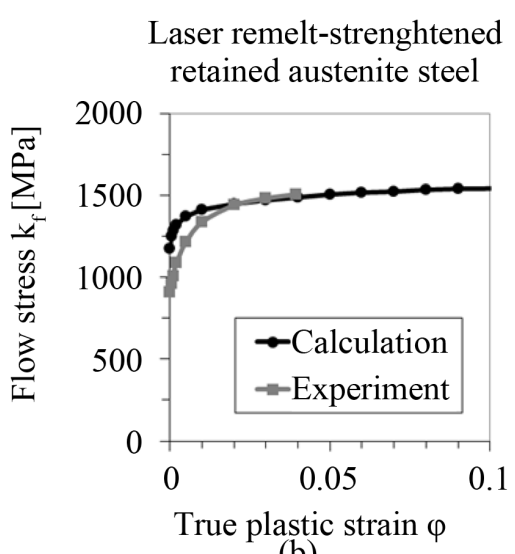

(b)

Figure 6. Comparisons of calculated and experimental flow curves of the laser track: Exemplary dual phase steel grade (a) and retained austenite steel grad (b).

\section{Shell modelling (full penetration of melting)}

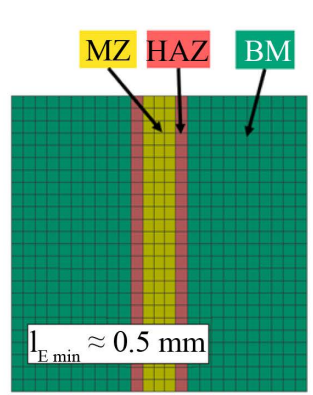

(a)

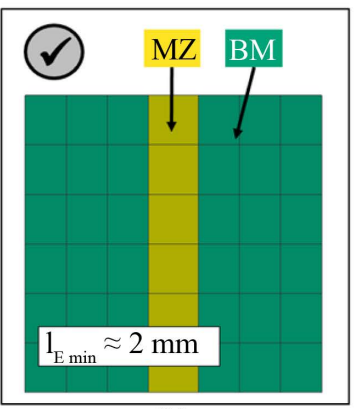

(b)

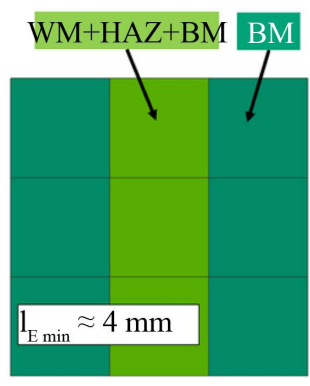

(c)

Meso-model $>$ Macro-model

Figure 7. Exemplary shell modelling possibilities for the full penetration condition and $1.5 \mathrm{~mm}$ sheet metal thickness.

passable element sizes must be considered (Figure 7(b)). Examinations in [9] showed, that 2-zone models lead to a sufficiently good accuracy. If the laser track depth does not correspond to the sheet thickness (e.g. Figure 2(c)), multi-layered shell elements can be used. These element types allow assigning different flow curves to the integration points over the element thickness. Furthermore, if even greater element sizes are necessary (e.g. low calculation capacity or very large models) all three zones (MZ, WM and BM) can be summed up into a mixed 1-zone element (Figure 7(c)). That only can be recommended for these exceptional cases, because of possibly significant loss in accuracy.

The optimization of especially crash components via local laser-strengthened structures is complex. In [9] different design approaches were developed. Basically the laser tracks should either be located at component areas with high plastic deformations or should follow the maximum principal stress (material flow), shown in Figure 8. It is furthermore essential to check the minimum distance between bordering laser tracks to avoid annealing effects. Laser track intersections should be avoided in general. Current investigations aim at the development of an optimization program which combines all design approaches and which automatically calculates the optimum laser track geometry according to the individual requirements (e.g. increase of crash performance, prevention of component damage).

\subsection{Laser-Strengthening of Crash Applications}

The specific crash performance requirements of car body structures vary for each country and test organization. The essential component load situations are nevertheless quite similar. A distinction can be made between 


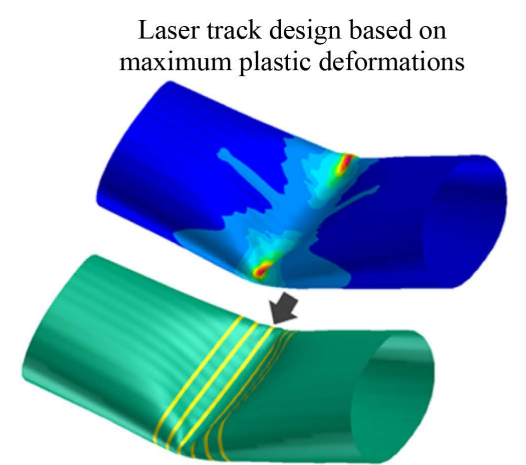

(a)

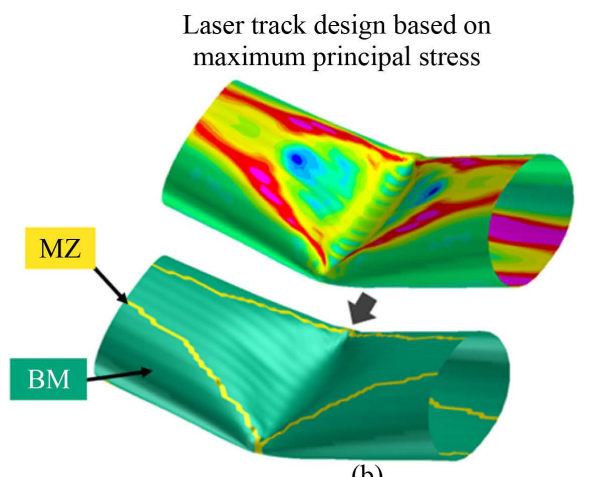

(b)

Figure 8. Laser track design approaches for a crash tube under 3-point-bending load (display detail): Laser track design based on the maximum plastic deformations (a) and based on the maximum principal stress (b).

compression and bending loads during crash deformation. Based on that, 2 typical crash situations were selected: The frontal crash usually generates compression loads at the longitudinal beam (Figure 9(a)), instead the frontal center pole impact situation generates bending loads at the cross beam (Figure 9(b)). For both test setups, steel tube profiles were applied.

At the frontal crash, both untreated and laser-strengthened tube profiles were simulated and tested. At the laser treated profiles longitudinal tracks were applied. Round about 15\% of the base metal volume have been laser-strengthened. The crash test results in Figure 9(a) show, that the compression range (intrusion) of the laser treated components were $12 \%$ lower compared to the untreated components. The results show a good correlation between simulation and experimental crash test. Further numerical optimization studies showed, that the same crash performance can be also achieved by a lower level of strengthened volume. But therefore quite complex track geometries must be developed and adapted to the load situation.

A significantly more efficient application is shown in Figure 9(b). Both untreated and laser-strengthened tube profiles were simulated and tested in the 3-point-bending test setup (according to the frontal center pole impact). Two different laser track geometries with less than 1\% strengthened component volume were developed. Compared to the untreated profiles, the part deflection (crash deformation) could be reduced by about 55\% only by adding 8 circular tracks (Figure 9 (b)).

In conclusion, the local laser treatment in terms of strengthening or softening can be used for optimizing the manufacturing process and as well as the component itself. The laser treatment technique is particularly efficient, if there are pronounced and localized load peaks in the component.

\subsection{Laser-Strengthening of Chassis Applications}

In addition to static and impact loads that are focused on chapter 3.2, automotive chassis components (Figure 10(a)) are also exposed to cyclic mechanical fatigue loadings. The significant improvement of the mechanical resistance to static or even impact loads could be demonstrated in previous sections. So the task here is to investigate the influence of the laser remelt-strengthened structures on the fatigue strength of automotive sheet materials. For the comparison of the different material behavior both the basic sheet material and laser-strengthened sheets were tested. The goal was to estimate the effect of the process and to derive conclusions for future component designs.

The test material (low alloyed steel grade: S355 J2 $+\mathrm{N}$ ) is typical for automotive chassis applications. The effects of shape (track orientation) and surface states were studied with respect to the achievable fatigue strengths and endurance limits. The experimental matrix includes the variations shown in Figure 10(b). The basic material state achieved a stress amplitude of $195 \mathrm{MPa}(100 \%)$ at $2 \times 10^{6}$ cycles (diagram in Figure 10, Basic material). The fatigue strength of specimens with one longitudinal laser track (untreated surface) only slightly reduces $(-10 \%)$, compared to the basic material (diagram in Figure 10, Untreated). However, the fatigue strength of ground down specimens with one longitudinal track improved the fatigue strength by about $+10 \%$, compared to the basic material (diagram in Figure 10, Ground). Due to the grinding process, the melt grooves were removed and a homogeneous roughness of $\mathrm{Rz} \sim 6 \mu \mathrm{m}$ across the entire surface could be ensured. 


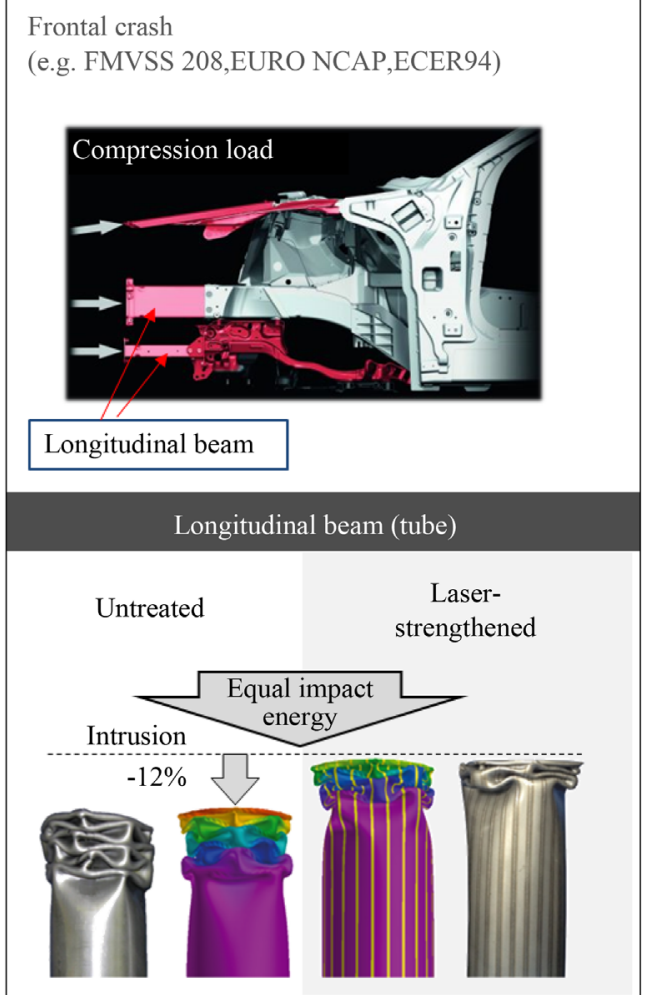

(a)

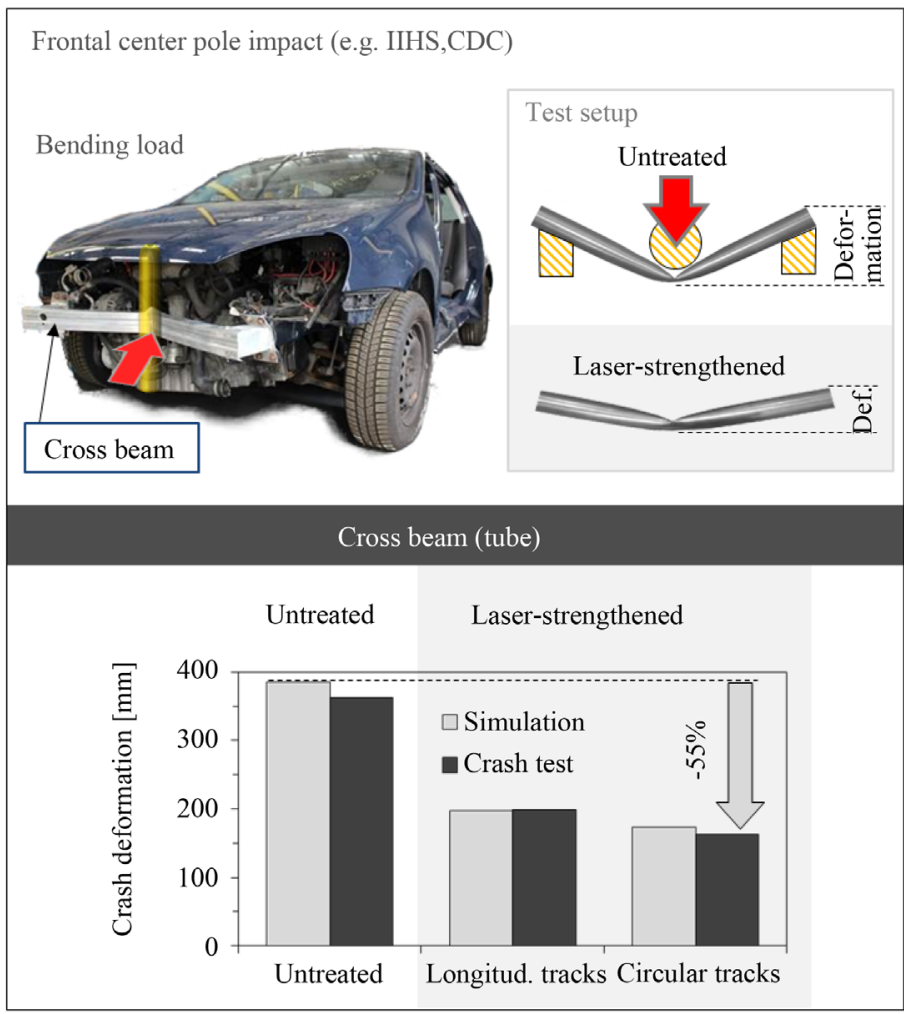

(b)

Figure 9. Simulation and experimental crash test results of local laser remelt-strengthened components: tube profiles under dynamic compression load (similar to Frontal crash) (a) (picture above taken from [23]), tube profiles under dynamic bending load (similar to Frontal center pole impact) (b).

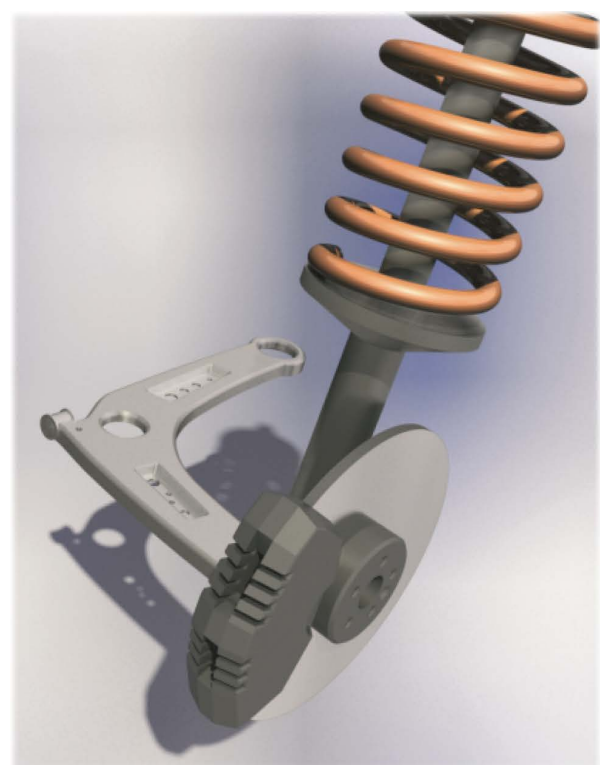

(a)
Fatigue strength tests

(Cycle number $\mathrm{N}=2 \times 10^{6}$ )

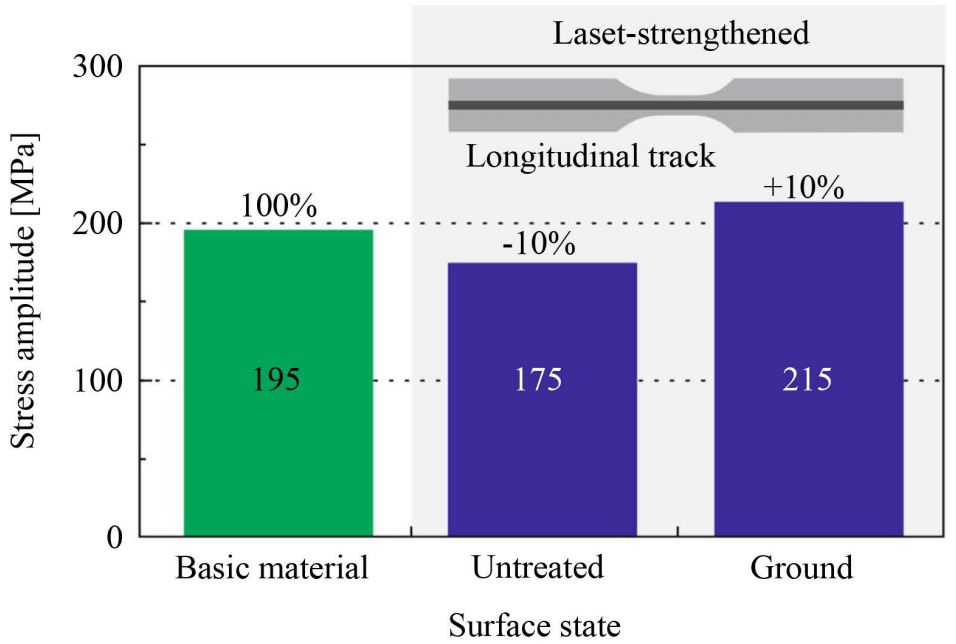

(b)

Figure 10. Automotive chassis assembly with a suspension arm made from welded sheets (a), results of fatigue strength tests for a cycle number of $\mathrm{N}=2 \times 10^{6}$ (b) [24].

Further FE calculations simulated a loading cycle by applying a static tensile load, which was subsequently relieved (1 cycle). As a result, a longitudinally oriented laser track works as a "tensile band" and reduces resi- 
dual deformations of the entire specimen, so that one can also expect improved fatigue strength.

Untreated (unground) samples with tracks oriented in parallel to the direction of the loading force, experience crack initiation at the edge of the track grooves. At the same loading conditions, the support due to the track reduces the maximum elongation and nearly compensates the detrimental effect of the groove. By additionally grinding the surface, the detrimental effect of the grooves could be eliminated. Accordingly, ground down samples with one longitudinal track show an improvement of the fatigue strength by about $+10 \%$, compared to the basic material. Principle differences in the levels of fatigue strength and endurance limit became apparent. For more detailed information regarding the fatigue behavior, the experimental matrix needs to be expanded (for further information see [25]).

The experiments showed that laser-strengthened tracks are useful for applications, in which the parts are exposed to cyclic loads in addition to static and impact loads. The technology significantly improves the resilience of chassis components especially in situations of impact misuse. Even further improvements are expected from process optimization, which may prevent an additional grinding process obsolete.

\section{Conclusions}

In the context of recent European and North American extensive agendas, leading to significant fuel and thus $\mathrm{CO}_{2}$ emissions, novel innovative lightweight automotive designs are becoming more and more essential. Apart from new lightweight material applications like steel-aluminum or even fiber-based hybrid structures, steel materials still play the leading role especially in large scale car body manufacturing. The paper shows an approach, how the lightweight potential of steel sheet structures can be significantly increased by a local laser treatment.

The main approach of local laser beam strengthening is the precise adaptation of the material and component properties to the specific load situation. The tensile strength of the laser-strengthened track can be 2.4 times higher compared to the base material. Because of the significant different material behavior between the 2 or even 3 zones, numerical descriptions for pre-designing components are essential. The paper shows how laser track depth, width and strength (in the form of flow curves) can be mathematically calculated, only be defining the material composition and basic laser process parameters. The results can be easily transferred into FE models, which typically are based on shell elements for sheet metal structures. The optimization especially of crash components via local laser-strengthened structures is complex. Therefore, current investigations aim at the development of an optimization program that combines different design approaches and automatically calculates the optimum laser track geometry according to the individual requirements (e.g. increase of crash performance, prevention of component damage).

Experimental tests show that local laser treatment can make a valuable contribution to novel lightweight designs, flexible car body manufacturing and passive vehicle safety. The crash behavior examinations show that the deformation of bumper components can be reduced by about $55 \%$, only by adding very small strengthened areas of approx. 1\%. Recent studies point out that even laser remelt-strengthened structures can be applied to chassis components to improve its performance under static, impact and fatigue loads.

In conclusion, the localized laser-strengthening process is a highly flexible, time and cost efficient tool to optimize even complex sheet metal components. The technique can be integrated into large-scale car body manufacturing, using already established laser technology that is also used for other processes.

\section{References}

[1] Friedrich, H.E. (2013) Leichtbau in der Fahrzeugtechnik. Springer Vieweg, Wiesbaden. http://dx.doi.org/10.1007/978-3-8348-2110-2

[2] Sonsino, C.M. (2008) Betriebsfestigkeit—Eine Einführung in die Begriffe und ausgewählte Bemessungsgrundlagen. MP Materials Testing, Carl Hanser Verlag, München, Vol. 50. http://dx.doi.org/10.3139/120.100862

[3] Mitschke, M. and Wallentowitz, H. (2014) Dynamik der Kraftfahrzeuge. Springer Vieweg, Wiesbaden. http://dx.doi.org/10.1007/978-3-658-05068-9

[4] Freytag, P. (2006) Technische Fortschritte vergrößern IHU-Potenzial. BLECH InForm, 5, 100-103.

[5] Lenze, F.-J. and Sikora, S. (2009) Verfahren zum Umformen von Platinen aus höher- und höchstfesten Stählen. European Patent Office, EP 2012948B1.

[6] Official Safety Assessment of the VW UP (2011). http://www.euroncap.com/de/results/vw/up!/11001

[7] Mende, O. (2011) VW Up! Karosserie und Sicherheitskonzept. In: ATZextra, Edition 09/2011, 26-31. 
[8] Wagner, M., Jahn, A., Standfuß, J., Brenner, B. and Beyer, E. (2014) Innovative Joining Technologies for MultiMaterial Lightweight Car Body Structures. Proceedings of the International Automotive Body Congress (IABC), Dearborn, 29-30 October 2014.

[9] Wagner, M. (2011) Simulation des Verformungsverhaltens laserverfestigter Karosseriestrukturen. Diploma Thesis, Fraunhofer IWS and TU Bergakademie Freiberg, Dresden.

[10] Wagner, M., Jahn, A. and Kröger, M. (2012) Belastungsangepasstes Bauteil- und Werkstoffdesign mithilfe lokaler Laserverfestigung. Lightweight Design, 5, 34-39.

[11] Birkert, A., Haage, S. and Straub, M. (2013) Umformtechnische Herstellung komplexer Karosserieteile. Springer Vieweg, Berlin, Heidelberg.

[12] Jahn, A., Heitmanek, M., Standfuß, J., Brenner, B., Donat, B., Wunderlich, G., Mickel, P. and Vogel, T. (2010) Lokale Laserbehandlung zur Steigerung der Crash-Belastbarkeit von Karosseriebauteilen. Conference Paper, Große Schweißtechnische Tagung 2010, Student Congress, Final Colloquium Integration des Rührreibschweißens in Fertigungsprozessketten, Nuremburg, 27-28th September 2010, DVS Media (DVS-Report 267).

[13] Jahn, A., Ahnert, M. and Kühn, T. (2009) Funktions- und werkstoffangepasste Laserbehandlung-Tailored Microstructuring von hochfesten Feinblechen. Final Report of Research Project Nr. S 769, Stiftung Industrieforschung, Fraunhofer IWS, Fraunhofer IWU, Dresden.

[14] Neugebauer, R., Beyer, E., Mauermann, R. and Standfuß, J. (2011) Lokale funktions- und werkstoffangepasste Wärmebehandlung_Lokales Laserhärten von hochfesten Blechstrukturen. Final Report of Fraunhofer FPP Program Strukturiertes Laserhärten, Fraunhofer IWU, Chemnitz and Fraunhofer IWS, Dresden.

[15] Jahn, A. (2009) Localizes Laser Strengthening to Improve Crash Behavior. Annual Report 2009, Fraunhofer IWS, Dresden. http://www.iws.fraunhofer.de/en/pressandmedia/publications/annual_reports.html

[16] Wagner, M. (2013) Laserverfestigte Fahrzeugcrashstrukturen-Wie die Fahrzeugmasse gesenkt und gleichzeitig die Crashsicherheit gesteigert werden kann. Journal of wt Werkstattstechnik Online, 103, 485-487.

[17] Heinzmann, M. (2016) Studie zur Bestimmung der Prozessgrenzen beim lokalen Laserstrahlumschmelzhärten von Karosseriefeinblechen. Minor Thesis, Fraunhofer IWS and TU Dresden, Dresden.

[18] Larour, P. (2010) Strain Rate Sensitivity of Automotive Sheet Steels: Influence of Plastic Strain, Strain Rate, Temperature, Microstructure, Bake Hardening And Pre-Strain. Ph.D. Thesis, Rhine-Westphalian Technical College of Aachen, Aachen.

[19] Hügel, H. And Graf, T. (2009) Laser in der Fertigung: Strahlquellen, Systeme, Fertigungsverfahren. Vieweg Teubner, Wiesbaden. http://dx.doi.org/10.1007/978-3-8348-9570-7

[20] Gref, W. (2005) Laserstrahlschweißen von Aluminiumwerkstoffen mit der Fokusmatrixtechnik. Ph.D. Thesis, University of Stuttgart, Stuttgart.

[21] Beyer, E. (1995) Schweißen mit Laser: Grundlagen. Springer Verlag, Aachen. http://dx.doi.org/10.1007/978-3-642-75759-4

[22] Doege, E., Meyer-Nolkemper, H. and Saeed, I. (1986) Fliesskurvenatlas metallischer Werkstoffe. München; Wien, Hanser.

[23] Crashsicherheit beim Audi A8, Audi Technology Portal (2011). http://www.audi-technology-portal.de/de/karosserie/steifigkeit-crashsicherheit/crashsicherheit

[24] Wagner, M. (2015) Laser Strengthened Steel Sheet Structures-Now Withstanding High Cyclic Loads! Fraunhofer IWS Annual Report 2015 (2015). (In Press). http://www.iws.fraunhofer.de/en/pressandmedia/publications/annual reports.html

[25] Holterhof, T. (2015) Schwingfestigkeit laserverfestigter Strukturen für die Anwendung in Fahrwerkskomponenten. Diploma Thesis, Fraunhofer IWS and TU Dresden, Dresden. 